\title{
ANALISIS PERHITUNGAN, PENCATATAN DAN PELAPORAN PAJAK PENGHASILAN PASAL 25 PADA CV. VENUS KUMERSOT RAYA
}

\author{
Triastuty Wulanjune Sejanto ${ }^{1}$, Inggriani Elim², Victorina Z. Tirayoh ${ }^{3}$ \\ ${ }^{1,2,3}$ Jurusan Akuntansi, Fakultas Ekonomi dan Bisnis, Universitas Sam Ratulangi, Jl. Kampus Bahu, Manado, \\ 95115, Indonesia
}

Email : Triastutysejanto@yahoo.com

\begin{abstract}
Income Tax Article 25 (Income Tax Article 25) shall be installment of income tax in installments. The objective is to alleviate the taxpayer's burden, since the tax payable must be paid within one year. This payment must be done alone and can not be represented. The purpose of this study to find out how the calculation, recording and reporting of Income Tax Article 25 on the $C V$. Venus Kumersot Raya. The method of analysis used in this research is descriptive with qualitative approach. The results of this study indicate that the calculation of Income Tax Article 25 conducted by the company has not been in accordance with the Act. Taxation No.36 Year 2008. This is evidenced by companies that do not allow for the recording and reporting of Income Tax Article 25 that has been done by the company every month is in accordance with applicable taxation provisions. CV. Venus Kumersot Raya has made taxes and taxes in the tax year of the 1771 Annual Tax Return, the berlin company may make appropriate tax payments on taxes and taxes in accordance.
\end{abstract}

Keywords: Calculation, Recording, Reporting, Income Tax Article 25

\section{PENDAHULUAN}

Di Indonesia, penerimaan pajak merupakan sumber penghasilan terbesar bagi negara. Dengan demikian pemerintah berusaha memasukkan uang sebanyak mungkin ke kas negara Kebijakan pemerintah untuk meningkatkan penerimaan negara yang bersumber dari pajak dilakukan melalui perluasan wajib pajak, perluasan objek pajak, perubahan tarif pajak dan penegakan hukum di bidang perpajakan. Apabila wajib pajak melakukan kesalahan perhitungan dan pembayaran pajak maka akan menghadapi sanksi pidana. Ada dua kemungkinan kesalahan dalam perhitungan dan pembayaran pajak, kemungkinan pertama karena tidak tahu, dan kemungkinan lain adalah karena kesengajaan atau kecurangan untuk melakukan penghindaran pajak. Agar terhindar dari kesalahan tersebut, semua wajib pajak harus terlebih dahulu memahami ketentuan peraturan perundang-undangan perpajakan.

Sejak reformasi peraturan dan sistem perpajakan tahun 1983, wajib pajak diberi kepercayaan penuh oleh undang-undang untuk menghitung, melaporkan, dan menyetor kewajiban pajaknya sendiri. Penyerahan kepercayaan ini menuntut wajib pajak harus memahami dengan baik ketentuan peraturan perundang-undangan perpajakan sebab di sisi lain undang-undang memberikan kewenangan kepada Direktorat Jendral Pajak untuk melakukan penegakan hukum yang akan berakibat pengenaan sanksi administratif pidana kepada wajib pajak.

Perhitungan pajak penghasilan badan seringkali terjadi perbedaan antara pajak penghasilan yang telah dihitung (komersial) dengan menurut fiskus. Hal ini disebabkan karena adanya perbedaan mengenai pengakuan pendapatan, biaya dan laba antara menurut perusahaan (komersial) dengan fiskus, maka perlu dilakukan penilaian mengenai cara perhitungan pajak penghasilan yang dilakukan oleh perusahaan dengan fiskus. Hal ini dimaksudkan untuk dapat menentukan pajak penghasilan badan (terutang) sesuai UndangUndang Perpajakan No. 36 Tahun 2008. 
CV Venus Kumersot Raya adalah salah satu perusahaan yang berada di Kabupaten Minahasa Utara, Sulawesi Utara yang bergerak di bidang industri. CV Venus Kumersot Raya adalah perusahaan air minum dalam kemasan (air mineral) yang bermerk "VENUSTAR" dalam kemasan botol plastik $(600 \mathrm{ml})$, di mana perusahaan melakukan pembayaran pajak yang salah satunya adalah pajak penghasilan badan yaitu Pajak Penghasilan Pasal 25. Oleh sebab itu dengan adanya sistem perpajakan yang ada, yaitu self assessment system maka CV. Venus Kumersot Raya harus melakukan perhitungan, pencatatan dan pelaporan Pajak Penghasilan pasal 25 sesuai dengan peraturan perundang-undangan yang berlaku.

\section{TINJAUAN PUSTAKA}

\subsection{Akuntansi}

Menurut Fitria (2014 : 2), memberikan pengertian akuntansi adalah ilmu dalam menghitung, mengukur, dan mencatat sebuah data keuangan menjadi sebuah informasi yang tepat, terukur, dan relevan untuk mengambil keputusan yang baik bagi perusahaan. Akuntansi adalah seni pencatatan, penggolongan, peringkasan, dan pelaporan transaksi-transaksi keuangan suatu organisasi dengan cara-cara tertentu yang sistematis serta penafsiran terhadap hasilnya (Mardiasmo, $2014: 1$ ).

\section{Laporan Keuangan}

Menurut Herry, (2015 : 18) laporan keuangan merupakan produk akhir dari serangkaian proses pencatatan dan pengikhtisaran data transaksi bisnis. Laporan keuangan adalah laporan yang menggambarkan kondisi keuangan dan hasil usaha suatu perusahaan pada saat tertentu atau jangka waktu tertentu Sofyan S, Harahap (2013 : 107).

\subsection{Pajak}

Menurut Suprianto (2014 : 1) menyatakan pajak adalah iuran atau pungutan wajib yang dipungut oleh pemerintah dari masyarakat (wajib pajak) untuk menutupi pengeluaran rutin negara dan biaya pembangunan tanpa balas jasa yang dapat ditunjuk secara langsung, namun secara logika pajak yang dibayar oleh masyarakat tersebut mempunyai dampak secara langsung terhadap kesejahteraan masyarakat seperti pembangunan jalan, jembatan, dan tempat-tempat umum lainnya.

\subsection{Pajak Penghasilan}

Menurut Resmi, (2014) yang dikutip dalam buku (Subadriyah, 2017 : 16) Pajak Penghasilan (PPh) adalah pajak yang dikenakan terhadap subjek pajak atas penghasilan yang diterima dan diperoleh dalam tahun pajak. Pajak Penghasilan (PPh) adalah pajak yang dikelola oleh pemerintah pusat dan memberikan kontribusi signifikan kepada penerimaan negara (Priantara 2013:171).

\subsection{Pajak Penghasilan Pasal 25}

Dalam buku perpajakan Mardiasmo (2018 : 153), Undang-Undang No. 7 Tahun 1984 yang mengatur tentang Pajak Penghasilan (PPh) berlaku sejak 1 Januari 1984 yang undangundangnya telah beberapa kali mengalami perubahan dan terakhir kali diubah dengan Undang-Undang Nomor 36 Tahun 2008. Pajak Penghasilan Pasal 25 (PPh Pasal 25) adalah pembayaran pajak penghasilannya dibayarkan setiap bulan dengan cara diangsurkan. Pajak Penghasilan Pasal 25 ini memiliki tujuan untuk setiap wajib pajak akan merasa diringankan beban wajib pajaknya, mengingat pajak yang akan terutang harus dilunasi dalam waktu satu tahun.

\section{Tarif Pajak Penghasilan Berdasarkan UU No. 36 Tahun 2008}

1. Berdasarkan Undang-Undang Pajak Penghasilan No. 17 tahun 2000, mengatur tarif pajak penghasilan yang diterapkan atas Penghasilan Kena Pajak bagi Wajib Pajak Badan dalam Negeri dan Bentuk Usaha Tetap (BUT) adalah sebagai berikut: 


\section{Tabel 2.2}

Tarif PPh Badan Sebelum Tahun 2009

\begin{tabular}{|l|c|}
\hline \multicolumn{1}{|c|}{ Lapisan Penghasilan Kena Pajak } & Tarif Pajak \\
\hline Sampai dengan Rp50.000.000 & $10 \%$ \\
\hline Di atas Rp50.000.000 s/d Rp100.000.000 & $15 \%$ \\
\hline Di atas Rp100.000.000 & $30 \%$ \\
\hline
\end{tabular}

\section{Sumber: Subadriyah (2017)}

Sedangkan sesuai dengan ketentuan yang baru Undang-Undang PPh No.36 tahun 2008 Pasal 17 besarnya tarif PPh yang diterapkan atas Penghasilan Kena Pajak (PKP) bagi Wajib Pajak (WP) Badan Dalam Negeri dan Bentuk Usaha Tetap

Tabel 2.3

Tarif WP Badan Dalam Negeri dan Bentuk Usaha Tetap (BUT)

\begin{tabular}{|c|c|c|}
\hline \multirow{4}{*}{$\begin{array}{c}\text { Berlaku Tarif Tunggal } \\
\text { ( Single Tax })\end{array}$} & Tahun Pajak & Tarif Pajak \\
\cline { 2 - 3 } & 2009 & $28 \%$ \\
\cline { 2 - 3 } & 2010 dan seterusnya & $25 \%$ \\
\hline
\end{tabular}

\section{Sumber: UU No. 36 Tahun 2008}

2. Fasilitas pengurangan tarif $\mathrm{PPh}$ badan diatur dalam Pasal 31 E. Wajib pajak badan dalam negeri dengan peredaran bruto s/d Rp50.000.000,000 mendapat fasilitas pengurangan tarif sebesar $50 \%$ yang dikenakan pajak dari peredaran bruto s/d Rp4.800.000.000.

\section{Perhitungan PPh Pasal 25}

Besarnya angsuran PPh Pasal 25 harus dihitung dengan ketentuan. Pada umumnya, cara menghitung PPh Pasal 25 didasarkan pada data SPT Tahunan tahun sebelumnya. Artinya, kita mengasumsi bahwa penghasilan tahun ini sama dengan penghasilan tahun sebelumnya. Tentu saja nanti akan ada perbedaan dengan kondisi sebenarnya ketika tahun pajak sekarang sudah berakhir. Selisih tersebut yang nantinya akan kita bayarkan sebagai kekurangan pajak akhir tahun atau yang biasa dinamakan sebagai PPh Pasal 29. Apabila selisihnya menunjukkan lebih bayar, maka kondisi ini dinamakan restitusi atau wajib pajak dapat meminta kelebihan pembayaran pajak yang telah dilakukan. Biasanya angsuran pajak tersebut adalah sebesar Pajak Penghasilan yang akan terutang menurut SPT Tahunan Pajak Penghasilan Pasal 21, 22, 23 dan Pasal 24, dibagi 12 (banyaknya bulan dalam bagian tahun pajak).

Misal, SPT Tahunan 2015 menunjukkan data sebagai berikut:

Pajak Penghasilan terutang

Kredit Penghasilan terutang

Maka, PPh Pasal 25 tahun 2016 yang harus dibayar

Rp35.000.000,00

tiap bulan adalah sebagai berikut:

Pajak Penghasilan terutang

Kredit Pajak PPh Pasal 21,22,23 dan 24

Rp50.000.000,00

$\underline{\mathrm{Rp} 35.000 .000,00}$

Jumlah

Rp15.000.000,00 
PPh Pasal 25 setiap bulan untuk tahun $2016=$

Jumlah pengurangan dari pajak

penghasilan terutang yang dikurangi dengan

kredit pajak : $12=$

Jadi, besarnya angsuran pajak yang harus dibayar sendiri setiap bulan untuk tahun 2016 adalah sebesar Rp1.250.000,00.

\section{Pencatatan Piutang PPh Pasal 25}

Dalam laporan keuangan komersil pada tahun pajak 2015 PT. MMM menghasilkan laba sebelum pajak sebesar Rp.xxx,- dari peredaran usaha sebesar Rp.xxx,- Setelah dilakukan koreksi fiskal diperoleh laba kena pajak sebesar Rp.xxx,- dan PPh terutang Rp.xxx,- (25\% x Rp.xxx,-)

Selama tahun 2015 data kredit pajak dan pajak yang dibayar sendiri PT. MMM adalah sebagai berikut:

$\begin{array}{ll}\text { PPh Pasal 22 Impor } & \text { Rp.xxx } \\ \text { PPh Pasal 22 Bendahara } & \text { Rp.xxx } \\ \text { PPh Pasal 23 } & \text { Rp.xxx } \\ \text { PPh Pasal 24 } & \text { Rp.xxx } \\ \text { PPh Pasal 25 } & \text { Rp.xxx }\end{array}$

Kredit pajak tersebut digunakan oleh PT. MMM untuk mengisi SPT Tahunan PPh Badan. Jurnal yang disiapkan PT. MMM untuk mencatat pajak penghasilan adalah sebagai berikut :

Jurnal :

Jurnal penyesuaian pada setiap akhir bulan untuk PPh Pasal 25
Dr.
Uang Muka PPh Pasal 25
Rp.xxx
Cr. Utang PPh Pasal 25
Rp.xxx

Pada saat dilakukan pembayaran PPh Pasal 25 dibuatkan jurnal:
Dr. Utang PPh Pasal 25
Rp.xxx
Cr. Kas
Rp.xxx

Sedangkan untuk bulan-bulan berikutnya perusahaan harus membuat jurnal yang sama tetapi dengan menggunakan nilai yang berbeda sesuai dengan perhitungan yang dilakukan.

Pada penutupan buku akhir tahun, jurnal yang disiapkan oleh pihak perusahaan adalah:
Dr. Beban PPh 25
Cr. Uang Muka PPh 25
Rp.xxx
Cr. Utang PPh Pasal 29
Rp.Xxx
Rp.xxx

\section{Pelaporan PPh Pasal 25}

Direktur Jenderal Pajak telah menerbitkan Peraturan Dirjen Nomor PER-22/PJ/200ㅁ․ Peraturan Dirjen ini mengatur tentang tatacara pembayaran dan pelaporan PPh Pasal 25. Sebagian besar isi dari ketentuan ini sebenarnya adalah sekedar kompilasi ketentuan dalam KUP tentang PPh Pasal 25 yang tersebar di peraturan-peraturan lain. Satu hal yang baru adalah masalah pelaporan PPh Pasal 25 bagi Wajib Pajak yang membayar PPh Pasal 25 melalui sisten Modul Penerimaan Negara (MPN).

\section{Koreksi Fiskal}

Untuk menghitung besarnya pajak penghasilan dengan dasar pembukuan adalah berdasarkan laba bersih. Laba bersih untuk menghitung Pajak Penghasilan adalah laba bersih menurut Undang-Undang Pajak Penghasilan laba bersih menurut akuntansi perusahaan. Laba bersih menurut Undang-Undang Pajak Penghasilan adalah laba bersih menurut akuntansi perusahaan (akuntansi komersial) yang telah disesuaikan dengan ketentuan dalam Undang- 
Undang Pajak Penghasilan akan menjadi laba bersih menurut pajak atau disebut Laba Bersih menurut Akuntansi Pajak.

\subsection{Penelitian Terdahulu}

Rayzah Tindagi (2014) dalam penelitian Analisis Perhitungan Pajak Penghasilan Badan Pada PT. Golden Mitra Inti Perkasa. Hasil penelitian menunjukkan bahwa perhitungan PPh yang dilakukan perusahaan belum sesuai dengan UU. Perpajakan No. 36 Tahun 2008 hal ini dibuktikan dengan perusahaan tidak menghitung fasilitas pengurangan tarif sebagaimana diatur pada Pasal 31E.

Raswin (2015) dalam penelitian Analisis Perhitungan Pajak Penghasilan Badan Pada PT. Amalia Jaya Pratama di Makassar. Hasil peelitian menunjukkan bahwa perhitungan dan pelaporan pajak penghasilan perusahaan tidak sesuai dengan Undang-Undang Pajak No. 36 Tahun 2008, dimana ada perbedaan dalam perhitungan pajak penghasilan. Kekurangan pajak penghasilan, karena dari laporan keuangan fiskal lebih besar dari kewajiban pajak atas laporan keuangan perusahaan.

\section{METODE PENELITIAN}

3.1. Jenis Penelitian

Jenis penelitian dalam penelitian ini adalah penelitian deskriptif dengan pendekatan kualitatif.

\subsection{Tempat dan Waktu Penelitian}

Penelitian di laksanakan di CV. Venus Kumersot Raya yang berlokasi di Desa Matungkas Kecamatan Dimembe Kabupaten Minahasa Utara. Penelitian dilakukan pada bulan Februari - April 2018.

\subsection{Metode Pengumpulan Data}

\section{Jenis Data}

Dalam melaksanakan analisis dan pembahasan terhadap masalah dalam penelitian ini penulis menggunakan data kualitatif dan kuantitatif.

\section{Sumber data}

Dalam penelitian ini penulis menggunakan data primer berupa tatacara pelaporan pajak dan data sekunder berupa profil dan struktur organisasi dari CV. Venus Kumersot Raya.

\section{Teknik Pengumpulan Data}

Dalam proses pengumpulan data yang diperlukan, penulis menggunakan 2 (dua) teknik/metode pengumpulan data yaitu:

a. Interview, yaitu mengadakan wawancara dalam hal ini tanya jawab dengan pimpinan dan staf yang ditujukan untuk mengadakan penelitian terhadap tata cara pelaporan yang menyangkut masalah tersebut.

b. Dokumenter, cara pengumpulan data dengan menggunakan arsip dan dokumen-dokumen dari perusahaan yang bersangkutan.

\subsection{Metode dan Proses Analisis}

Analisis yang dilakukan penulis dalam menyelesaikan permasalahan dalam penelitian ini adalah dengan menggunakan metode analisis deskriptif kualitatif. Dalam penelitian ini, penulis akan mempelajari laporan keuangan dan Surat Pemberitahuan Pajak Tahunan yang diperoleh dari perusahaan. Kemudian dianalisis apakah proses perhitungan, pencatatan dan pelaporan Pajak Penghasilan Pasal 25 yang dibuat tersebut sudah benar dan telah sesuai dengan peraturan perundang-undangan yang berlaku saat ini. 


\section{HASIL PENELITIAN DAN PEMBAHASAN}

\subsection{Hasil Penelitian}

\section{Perhitungan PPh Pasal 25}

Berikut disajikan perhitungan Pajak Penghasilan Pasal 25 dari CV. Venus Kumersot Raya yang dilakukan oleh perusahaan berdasarkan data yang tercantum dalam Catatan Atas Laporan Keuangan CV. Venus Kumersot Raya yang terlampir.

Perhitungan Pajak Penghasilan Pasal 25

- $\quad$ Peredaran Usaha Bruto

o Jumlah Peredaran Bruto Pada Tahun 2016:

- $\quad$ Penjualan Rp.1.525.000.000,00

Dalam perhitungan PPh Pasal 25 CV. Venus Kumersot Raya sesuai data SPT 1771 tahun 2015, diketahui perusahaan menggunakan tarif normal dalam perhitungan $\mathrm{PPh}$ terutang badan, yaitu tarif Pasal 17 ayat 2 b sebesar $25 \%$ yang diberlakukan sejak tahun 2010 . Sebelum dilakukan koreksi fiskal perusahaan menggunakan penghasilan kena pajak yang belum memerhatikan koreksi fiskal dan perhitungan tarif 31 E sebagai berikut:

Diketahui:

PKP/ Penghasilan Kena Pajak $\quad=$ Rp106.775.000,00

PPh Terutang

$$
\begin{aligned}
& =25 \% \times \mathrm{Rp} 106.775 .000,00 \\
& =\mathrm{Rp} 26.693 .750,00
\end{aligned}
$$

Jadi untuk PPh terutang badan pada tahun 2016, CV. Venus Kumersot Raya sebesar Rp26.693.750,00 dengan menggunakan tarif Pasal 17 ayat 2a sebesar $25 \%$.

\section{Pencatatan PPh Pasal 25}

Pencatatan PPh Pasal 25 yang dilakukan CV. Venus Kumersot Raya untuk tahun 2016 didapatkan dari Surat Pemberitahun Pajak Tahun 2014, sebagai berikut: Laba Kena Pajak Tahun $2015=$ Rp6.720.000,00 : $12=$ Rp560.000,00. Adapun angka tersebut untuk digunakan untuk bulan Januari, Februari dan Maret Tahun 2016 dan pencatatan yang dilakukan adalah sebagai berikut:

- Jurnal penyesuaian pada tanggal 31 Januari 2016
Dr. Uang Muka PPh 25
Rp560.000,00

Cr. Utang PPh Pasal 25

Rp560.000,00

dan pada saat dilakukan pembayaran PPh Pasal 25 untuk bulan Januari 2016 yang dibayarkan pada tanggal 5 Februari 2016 dibuatkan jurnal :

Dr. Utang PPh Pasal 25

Rp560.000,00

Cr. Kas

Rp560.000,00

- Jurnal Penyesuaian pada tanggal 29 Februari 2016

Dr. Uang Muka PPh 25

Rp560.000,00

Cr. Utang PPh Pasal 25

Rp560.000,00

dan pada saat dilakukan pembayaran PPh Pasal 25 untuk bulan Februari 2016 yang dibayarkan pada tanggal 8 Maret 2016 dibuatkan jurnal :

Dr. Utang PPh Pasal 25

Rp560.000,00

Cr. Kas

$\begin{array}{ll}\text { - Jurnal Penyesuaian pada tanggal } 31 \text { Maret } 2016 \\ \text { Dr. Uang Muka PPh } 25 & \text { Rp560.000,00 }\end{array}$

$\begin{array}{ll}\text { - Jurnal Penyesuaian pada tanggal } 31 \text { Maret } 2016 \\ \text { Dr. Uang Muka PPh } 25 & \text { Rp560.000,00 }\end{array}$

Cr. Utang PPh Pasal 25

$\begin{array}{ll}\text { - Jurnal Penyesuaian pada tanggal } 31 \text { Maret } 2016 \\ \text { Dr. Uang Muka PPh } 25 & \text { Rp560.000,00 }\end{array}$

Rp560.000,00

dan pada saat dilakukan pembayaran PPh Pasal 25 untuk bulan Maret 2016 yang dibayarkan pada tanggal 7 April 2016 dibuatkan jurnal :

Dr. Utang PPh Pasal 25

Cr. Kas

Rp560.000,00

Sedangkan untuk bulan April dan bulan-bulan berikutnya perusahaan masih membuat jurnal yang sama dengan bulan Januari-Maret 2016 tetapi dengan menggunakan nilai yang 
berbeda dari nilai Rp560.000,00. Hal ini disebabkan karena CV. Venus Kumersot Raya sudah melaporkan SPT 2016 dan nilai yang digunakan adalah nilai angsuran yang diambil dari SPT tersebut yaitu sebesar Rp1.360.000,00. Jurnal penyesuaian yang dibuat untuk mencatat Uang Muka PPh Pasal 25 dan Utang PPh Pasal 25 dengan jurnal seperti di bawah ini :

- $\quad$ Jurnal penyesuaian pada tanggal 30 April 2016

Dr. Uang Muka PPh 25

Cr. Utang PPh Pasal 25

Rp1.360.000,00

$\mathrm{Rp} 1.360 .000,00$

dan pada saat dilakukan pembayaran PPh Pasal 25 untuk bulan April 2016 yang dibayarkan pada tanggal 9 Mei 2016 dibuatkan jurnal :

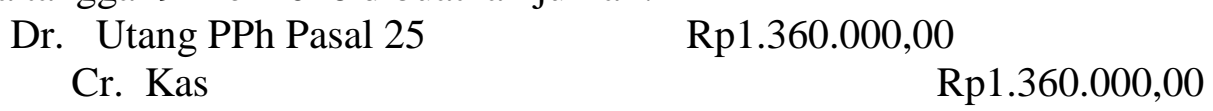

Jurnal di atas ini disiapkan setiap akhir bulan sampai dengan bulan Desember 2016 sedangkan untuk pembayarannya dicatat berdasarkan tanggal dimana Utang PPh Pasal 25 dibayarkan. Jika diringkas daftar PPh Pasal 25 CV. Venus Kumersot Raya tahun 2016 menjadi sebagai berikut:

Tabel 4.3

CV. Venus Kumersot Raya

Buku Besar Uang Muka PPh 25

Per 31 Desember 2016

\begin{tabular}{|c|c|c|c|c|c|}
\hline Bulan & Tgl & Keterangan & Debit & Kredit & Saldo \\
\hline Januari & 31 & Jurnal Memorial & 560.000 & 0 & 560.000 \\
\hline Februari & 29 & Jurnal Memorial & 560.000 & 0 & 1.120 .000 \\
& & & & & \\
\hline Maret & 31 & Jurnal Memorial & 560.000 & 0 & 1.680 .000 \\
\hline April & 30 & Jurnal Memorial & 1.360 .000 & 0 & 3.040 .000 \\
\hline Mei & 31 & Jurnal Memorial & 1.360 .000 & 0 & 4.400 .000 \\
\hline Juni & 30 & Jurnal Memorial & 1.360 .000 & 0 & 5.760 .000 \\
\hline Juli & 30 & Jurnal Memorial & 1.360 .000 & 0 & 7.120 .000 \\
\hline Agustus & 31 & Jurnal Memorial & 1.360 .000 & 0 & 8.480 .000 \\
\hline September & 30 & Jurnal Memorial & 1.360 .000 & 0 & 9.840 .000 \\
\hline Oktober & 31 & Jurnal Memorial & 1.360 .000 & 0 & 11.200 .000 \\
\hline November & 30 & Jurnal Memorial & 1.360 .000 & 0 & 12.560 .000 \\
\hline Desember & 31 & Jurnal Memorial & 1.360 .000 & 0 & 13.920 .000 \\
\hline Desember & 31 & Jurnal Memorial & 0 & 13.920 .000 & 0 \\
\hline
\end{tabular}

Sumber: Data Olahan

Pada penutupan buku 31 Desember 2016, rekening Uang Muka PPh Pasal 25 yang ada di Neraca di sisi Aktiva pada kelompok Aktiva Lancar dikreditkan dan dilawankan dengan Rekening Beban Pajak sebelah Debit sehingga saldo Uang Muka Pajak tidak muncul lagi di

sebelah aset dengan jurnal yang akan dibahas di halaman berikutnya. Jurnal yang disiapkan oleh pihak perusahaan, adalah :

Dr. Beban PPh Pasal 25
Cr. Uang Muka PPh Pasal 25
Cr. Utang PPh Pasal 29

Rp26.693.750,00

Rp13.920.000,00

Rp12.773.750,00

Dengan membuat jurnal di atas maka buku besar untuk Utang PPh Pasal 25 dapat dilihat seperti di bawah ini : 


\section{Tabel 4.4}

CV. Venus Kumersot Raya

Buku Besar Utang PPh 25

Per 31 Desember 2016

\begin{tabular}{|c|c|c|c|c|c|}
\hline Bulan & Tgl & Keterangan & $\begin{array}{l}\text { Debit } \\
\text { (Rp.) }\end{array}$ & $\begin{array}{c}\text { Kredit } \\
\text { (Rp.) }\end{array}$ & $\begin{array}{l}\text { Saldo } \\
\text { (Rp.) }\end{array}$ \\
\hline \multirow[t]{3}{*}{ Januari } & 01 & Saldo Awal & 0 & 0 & 560.000 \\
\hline & 08 & Bayar PPh 25 & 560.000 & 0 & 0 \\
\hline & 31 & Jurnal Memorial & 0 & 560.000 & 560.000 \\
\hline \multirow[t]{2}{*}{ Februari } & 05 & Bayar PPh 25 & 560.000 & 0 & 0 \\
\hline & 29 & Jurnal Memorial & 0 & 560.000 & 560.000 \\
\hline \multirow[t]{2}{*}{ Maret } & 08 & Bayar PPh 25 & 560.000 & 0 & 0 \\
\hline & 31 & Jurnal Memorial & 0 & 560.0000 & 560.000 \\
\hline \multirow[t]{2}{*}{ April } & 07 & Bayar PPh 25 & 560.000 & 0 & 560.000 \\
\hline & 30 & Jurnal Memorial & 0 & 1.360 .000 & 1.360 .000 \\
\hline \multirow[t]{2}{*}{ Mei } & 09 & Bayar PPh 25 & 1.360 .000 & 0 & 0 \\
\hline & 31 & Jurnal Memorial & 0 & 1.360 .000 & 1.360 .000 \\
\hline \multirow[t]{2}{*}{ Juni } & 07 & Bayar PPh 25 & 1.360 .000 & 0 & 0 \\
\hline & 30 & Jurnal Memorial & 0 & 1.360 .000 & 1.360 .000 \\
\hline \multirow[t]{2}{*}{ Juli } & 11 & Bayar PPh 25 & 1.360 .000 & 0 & 0 \\
\hline & 30 & Jurnal Memorial & 0 & 1.360 .000 & 1.360 .000 \\
\hline \multirow[t]{2}{*}{ Agustus } & 08 & Bayar PPh 25 & 1.360 .000 & 0 & 0 \\
\hline & 31 & Jurnal Memorial & 0 & 1.360 .000 & 1.360 .000 \\
\hline \multirow[t]{2}{*}{ September } & 06 & Bayar PPh 25 & 1.360 .000 & 0 & 0 \\
\hline & 30 & Jurnal Memorial & 0 & 1.360 .000 & 1.360 .000 \\
\hline \multirow[t]{2}{*}{ Oktober } & 05 & Bayar PPh 25 & 1.360 .000 & 0 & 0 \\
\hline & 31 & Jurnal Memorial & 0 & 1.360 .000 & 1.360 .000 \\
\hline \multirow[t]{2}{*}{ November } & 07 & Bayar PPh 25 & 1.360 .000 & 0 & 0 \\
\hline & 30 & Jurnal Memorial & 0 & 1.360 .000 & 1.360 .000 \\
\hline \multirow[t]{3}{*}{ Desember } & 05 & Bayar PPh 25 & 1.360 .000 & 0 & 0 \\
\hline & 31 & Jurnal Memorial & 0 & 1.360 .000 & 1.360 .000 \\
\hline & 31 & Jurnal Memorial & 0 & 12.773 .750 & 14.133 .750 \\
\hline
\end{tabular}

Sumber: Data Olahan

Pada bulan April 2017, CV. Venus Kumersot Raya menyetorkan Pajak Penghasilan Pasal 29 ke kas negara melalui bank sebesar Rp12.773.750,00.

Dan atas pembayaran tersebut dicatat:

Dr. Utang PPh Pasal 29

Cr. Kas

Rp12.773.750,00

Rp12.773.750,00

Jurnal diatas akan:

(-). Menghapus Utang PPh Badan (yang kelihatan pada Neraca 31 Desember 2016).

(-) Mengurangi Kas Perusahaan pada bulan Maret 2017 sebesar Rp.12.773.750,00.

Selanjutnya, Lump-sum (PPh Pasal 25) CV. Venus Kumersot Raya untuk tahun 2017 adalah sebesar Rp.26.693.750/12 = Rp.2.224.479,17. Berlaku mulai masa bulan April yang akan dibayarkan bulan Mei 2017.

Pelaporan PPh Pasal 25

Sebagaimana diatur dalam Undang-Undang Ketentuan Umum dan Tata Cara Perpajakan (KUP), CV. Venus Kumersot Raya menggunakan Surat Pemberitahuan (SPT) 
sebagai suatu sarana untuk melaporkan dan mempertanggung jawabkan penghitungan jumlah pajak yang terutang. Pelaporan pajak pada CV. Venus Kumersot Raya disampaikan ke Kantor Pelayanan Pajak (KPP) dimana WP terdaftar, dalam hal ini KPP Pratama Bitung.

\subsection{Pembahasan}

Dalam hasil penelitian pada CV. Venus Kumersot Raya, dapat dilihat bahwa perusahaan telah membuat Laporan Laba/Rugi yang sesuai dengan Standar Akuntansi Keuangan tapi belum memegang prinsip undang-undang perpajakan. Hal ini membuat sistem pembayaran pajak jadi terganggu, akan lebih baik jika dalam laporan laba-rugi juga dimasukan data koreksi fiskal positif seperti yang akan dipaparkan berikut ini.

Dalam tabel 4.2 Laporan Laba/Rugi perusahaan yang harus dilakukan penyesuaian, di antaranya:

1. Biaya Jamuan Tamu sebesar Rp7.750.000,00

2. Biaya Entertainment sebesar Rp5.000.000,00

3. Biaya Lain sebesar Rp6.250.000,00

Karena perusahaan CV. Venus Kumersot Raya tidak ada lampiran daftar normatif maka Biaya Jamuan Tamu sebesar Rp7.750.000,00, Biaya Entertainment sebesar Rp5.000.000,00, dan Biaya Lain sebesar Rp6.250.000,00 sebaiknya dikoreksi fiskal positif agar perusahaan tidak mendapat resiko saat pemeriksaan dari fiskus. Jadi, dalam koreksi fiskal akun biaya/beban jamuan tamu, biaya/beban entertainment dan biaya/beban lain dalam laporan laba-rugi komersial tersebut harus dikoreksi positif sesuai dengan jumlah biaya-biaya tersebut.

\section{Laba Bersih Sebelum Pajak Penghasilan \\ Menurut Akuntansi}

Koreksi Fiskal Positif :

1. Biaya Jamuan Tamu

2. Biaya entertainment

3. Biaya lain

\section{Jumlah Koreksi Fiskal Positif}

\section{Laba Sebelum Pajak Penghasilan Menurut}

Fiskal (Laba Fiskal)

$$
\begin{aligned}
& =\mathrm{Rp} 7.750 .000,00 \\
& =\mathrm{Rp} 5.000 .000,00 \\
& =\mathrm{Rp} 6.250 .000,00
\end{aligned}
$$

$$
=\text { Rp106.775.000,00 }
$$

Jadi berdasarkan data koreksi fiskal yang diperoleh, diketahui bahwa laba sebelum pajak menurut akuntansi dari CV. Venus Kumersot Raya adalah sebesar Rp106.775.000,00 kemudian dilakukan koreksi fiskal positif sebesar Rp19.000.000,00 yang terdiri dari Biaya/beban Jamuan Tamu sebesar Rp7.750.000,00 ; Biaya/beban Entertaiment sebesar Rp5.000.000,00 dan Biaya/beban lain sebesar Rp6.250.000,00. Koreksi positif tersebut akan mengakibatkan bertambahnya laba sebelum pajak menurut akuntansi dari CV. Venus Kumersot Raya yang berjumlah Rp106.775.000,00 bertambah sejumlah koreksi fiskal positif yaitu Rp19.000.000,00 menjadi laba sebelum pajak menurut fiskal (laba fiskal) sejumlah Rp125.775.000,00.

\section{Perhitungan PPh Pasal 25}

$\mathrm{CV}$. Venus Kumersot Raya dalam Perhitungan PPh Pasal 25 nya, perusahaan mengalami kekeliruan dalam perhitungan $\mathrm{PPh}$ terutang menurut perpajakan perusahaan harus memperhatikan koreksi fiskal dalam perhitungan PPh badan, untuk memperoleh laba fiskal, yang nantinya akan digunakan untuk perhitungan PPh Badan terutang. Dalam penyesuaian/ koreksi fiskal di atas sudah sesuai dengan Undang-Undang Perpajakan, diperoleh laba fiskal dari koreksi positif sebesar Rp125.775.000,00. Akun yang dikoreksi positif yaitu, biaya jamuan tamu sebesar Rp7.750.000,00 biaya entertainment sebesar Rp5.000.000,00 dan biaya lain sebesar Rp6.250.000,00 yang akan mengakibatkan meningkatnya laba perusahaan setelah dilakukan koreksi positif. Dari laba sebelum pajak Rp106.775.000,00 menjadi 
Rp125.775.000,00 dengan selisih sebesar Rp19.000.000,00 yang telah sesuai dengan Undang-undang Perpajakan.

Untuk Perhitungan PPh Badan terutang, perusahaan tidak memperhatikan adanya tarif PPh Pasal 31E berdasarkan Undang-undang No. 36 Tahun 2008, yang mana tarif ini memberikan potongan bagi wajib pajak dalam negeri dengan peredaran bruto di bawah 4.800.000.000,00 (empat miliar delapan ratus juta rupiah) dan, s.d 50.000.000.000,00 (lima puluh miliar), mendapat faslitas berupa pengurangan tarif sebesar 50\% dari tarif sebagaimana dimaksud dalam pasal 17 ayat 2 a sebesar $25 \%$, Peredaran bruto S.d $4.8 \mathrm{M}(50 \%$ x 25\%)= $12,5 \%$.

Dalam catatan atas laporan keuangan di atas peredaran bruto CV. Venus Kumersot Raya Tahun 2017 sebesar Rp1.525.000.000,00 yang mana peredaran bruto perusahaan tersebut diperkenankan menggunakan tarif $\mathrm{PPh}$ pasal $31 \mathrm{E}$ karena peredaran bruto perusahaan tidak melebihi Rp4.8M, dengan perhitungan setelah diperoleh laba fiskal dengan melakukan koreksi fiskal menurut perpajakan sebagai berikut:

Peredaran Bruto/Omset

PKP (Penghasilan kena pajak)

PPH Terutang

$$
\begin{aligned}
& =\mathrm{Rp} 1.525 .000 .000,00 \\
& =\mathrm{Rp} 125.775 .000,00 \\
& =50 \% \times 25 \% \times 125.775 .000,00 \\
& =\mathrm{Rp} 15.721 .875,00
\end{aligned}
$$

Dalam pembayaran pajak perusahaan yang menggunakan tarif 17 ayat $2 \mathrm{~b}$ dan tidak menggunakan tarif pasal $31 \mathrm{E}$, yang berdasarkan Undang-undang No 36 Tahun 2008. Akan berbeda, tarif 17 ayat 2b diperoleh PPh Terutang Badan sebesar Rp26.693.750,00 dan dengan menggunakan tarif pasal 31 E diperoleh PPh terutang Badan sebesar Rp15.721.875.

Tabel 4.5

Perbandingan PPh Terutang

\begin{tabular}{|c|c|c|}
\hline Keterangan & $\begin{array}{c}\text { Perhitungan Perusahaan } \\
(\mathbf{R p})\end{array}$ & $\begin{array}{c}\text { Hasil Analisis } \\
\text { (Rp) }\end{array}$ \\
\hline Penghasilan Kena Pajak & 106.775 .000 & 125.775 .000 \\
\hline PPh Terutang & 26.693 .750 & 15.721 .875 \\
\hline Laba/Rugi Setelah Pajak & 80.081 .250 & 99.081 .250 \\
\hline
\end{tabular}

Sumber: Data Olahan.

Sesuai peraturan perpajakan, telah dilakukan beberapa koreksi fiskal yang mengakibatkan laba kena pajak CV. Venus Kumersot Raya. Laba bersih dalam laporan laba rugi komersial adalah Rp80.081.250,00 sedangkan laba bersih setelah dikoreksi fiskal adalah sebesar Rp99.081.250,00 dan hal itu tentu saja mempengaruhi jumlah pajak yang harus dibayar. Sebelum dilakukan koreksi fiskal, CV. Venus Kumersot Raya harus membayar pajak sebesar Rp26.693.750,00 setelah dilakukan koreksi fiskal dan dengan menggunakan tarif pasal 31 E, CV. Venus Kumersot Raya harus membayar pajak sebesar Rp15.721.875,00 hal ini telah sesuai dengan Undang-undang perpajakan yang berlaku.

\section{Pencatatan PPh Pasal 25}

Berdasarkan hasil penelitian yang ada, dapat dikatakan bahwa Pencatatan Pajak Penghasilan Pasal 25 pada CV. Venus Kumersot Raya sudah sesuai dengan ketentuan umum dan tata cara perpajakan yang berlaku.

\section{Pelaporan PPh Pasal 25}

CV. Venus Kumersot Raya melakukan pelaporan Pajak Penghasilan (PPh) Pasal 25 setiap tahun dengan menggunakan Surat Pemberitahuan (SPT) dan pelaporan pajak CV. 
Venus Kumersot Raya disampaikan ke Kantor Pajak Pratama Bitung dimana wajib pajak terdaftar.

\section{PENUTUP}

\subsection{Kesimpulan}

Berdasarkan hasil penelitian dan pembahasan yang telah dilakukan pada CV. Venus Kumersot Raya, maka dapat ditarik kesimpulan sebagai berikut.

1. Berdasarkan hasil penelitian yang sudah dilakukan, Perhitungan Pajak Penghasilan Pasal 25 yang dilakukan oleh perusahaan belum sesuai dengan Undang-Undang Perpajakan No. 36 Tahun 2008. Hal ini dibuktikan dengan perusahaan CV. Venus Kumersot Raya tidak menghitung fasilitas pengurangan tarif sebagaimana diatur pada Pasal 31 E.

2. Pencatatan dan Pelaporan $\mathrm{PPh}$ Pasal 25 yang telah dilakukan oleh CV. Venus Kumersot Raya setiap bulannya sudah sesuai dengan Undang-Undang Perpajakan Nomor 36 Tahun 2008.

3. Koreksi fiskal sangat perlu dilakukan karena dapat membantu dalam rangka perhitungan pajak penghasilan badan dari CV. Venus Kumersot Raya, sehingga pihak $\mathrm{CV}$. Venus Kumersot Raya dapat melakukan pembayaran pajak secara benar sesuai dengan peraturan perpajakan yang berlaku.

4. Terdapat 3 akun yang dikoreksi fiskal positif dalam laporan laba-rugi komersial CV. Venus Kumersot Raya. Pertama, yaitu Biaya Jamuan Tamu sebesar Rp7.750.000,00, kedua adalah Biaya Entertaiment sebesar Rp5.000.000,00, dan ketiga adalah Biaya Lain sebesar Rp6.250.000,00. koreksi positif mengakibatkan bertambahnya laba kena pajak CV. Venus Kumersot Raya 31 Desember 2016 sejumlah Rp19.000.000,00.

\subsection{Saran}

Berdasarkan pembahasan dan kesimpulan yang telah diuraikan terdapat beberapa saran yang dapat diberikan untuk CV. Venus Kumersot Raya yaitu, sebagi berikut:

1. CV. Venus Kumersot Raya harus membuat penyesuaian fiskal/koreksi fiskal dalam membuat laporan laba-rugi perusahaan dan memperhatikan koreksi fiskal dalam pengisian SPT Tahunan 1771, sehingga perusahaan dapat selalu melakukan pembayaran pajak penghasilan yang benar berdasarkan dengan laba kena pajak menurut fiskal dan sesuai dengan peraturan perpajakan yang berlaku. Perusahaan harus lebih memperhatikan aspek-aspek yang harus dikoreksi fiskal sesuai dengan peraturan perpajakan yang berlaku atas pengakuan pendapatan-pendapatan dan bebanbeban, agar supaya dapat dilakukan penyesuaian fiskal yang tepat, dan memperhatikan pengisian koreksi fiskal dalam pengisian SPT Tahunan Badan 1771, sehingga tidak terdapat kekeliruan dalam pembayaran dan pelaporan pajak.

2. CV. Venus Kumersot Raya sebaiknya menggunakan tarif pasal 31 E berdasarkan Undang- Undang Nomor 36 Tahun 2008 dalam perhitungan pajak penghasilan terutang badan sesuai dengan peredaran bruto, perusahaan mendapat potongan $50 \%$ dari tarif normal $25 \%$ adalah sebesar $12.5 \%$, sehingga $\mathrm{PPh}$ terutang badan menjadi lebih kecil dari perhitungan badan sebelumnya yang menggunakan tarif 17 ayat $2 \mathrm{~b}$. Dengan demikian dalam pengisian dan pelaporan pajak badan dalam SPT Tahunan Badan perusahaan dapat melaporkan pajak berdasarkan tarif pasal $31 \mathrm{E}$. 


\section{DAFTAR PUSTAKA}

Fitria, Dina. 2014. Buku Pintar Akuntansi. Penerbit Laskar Aksara. Jakarta Timur.

Harahap, S. Sofyan. 2013. Analisis Kritis Atas Laporan Keuangan. Edisi Satu. PT Raja Grafindo Persada. Jakarta.

Hery. 2015. Pengantar Akuntansi, Comprehensive Edition. Penerbit PT Gransindo, Anggota Ikapi. Jakarta.

Mardiasmo. 2018. Perpajakan. Edisi Terbaru 2018. Andi. Yogyakarta.

Priantara Diaz. 2013. Perpajakan Indonesia. Edisi 2 Revisi. Mitra Wacana Media. Jakarta.

Prof. Dr. Mardiasmo, MBA, Ak, 2014, Sujarweni. 2015. Akuntansi Sektor Publik. Pustaka Baru Press. Yogyakarta.

Raswin. 2014. Analisis Perhitungan Pajak Penghasilan Badan Pada PT. Amalia Jaya Pratama di Makassar. Skripsi. Universitas Bosowa.

Rayzah Tindagi. 2014. Analisis Perhitungan Pajak Penghasilan Badan pada PT. Golden Mitra Inti Perkasa. Skripsi. Universitas Sam Ratulangi (UNSRAT). Manado.

Resmi, Siti. 2014. Perpajakan Teori dan Kasus. Salemba Empat. Jakarta.

Subadriyah. 2017. Pajak Penghasilan. Pustaka Belajar.Yogyakarta

Supryanto, Eddy. 2014. Akuntansi Perpajakan. Edisi Pertama. Graha Ilmu. Yogyakarta

Undang-Undang Republik Indonesia Nomor 36 Tahun 2008 tentang perubahan keempat atas Undang-Undang Nomor 7 tahun 1983 Tentang Pajak Penghasilan, Jakarta. 